\title{
Achieving Visibility: Midlife and Older Women's Practices on Instagram and Blogs
}

\author{
Laura McGrath - Kennesaw State University \\ KEYWORDS \\ identity; age; social media; Instagram; performance; gender; visibility
}

n literacy and composition studies, much of what we know about the literate practices
of social media users comes from research on youth and young adults (e.g., Amicucci;
boyd; Buck; Ito, et al.; Pigg; Shepherd, "FB in FYC" and "Men, Women and Web 2.0
Writing"; Tomlinson; Warner). Despite evidence of social media use across the life
course (Smith and Anderson), the literate activities of midlife and older adults on social media remain under-researched, leaving us with an incomplete perspective on digital literacy practices. In order to help address this gap and contribute new knowledge on digital literacy across the life course, I present the results of observational and survey research on the literate activities of an active community of Instagrammers (users who contribute content to the social media platform Instagram) who range in age from approximately fifty-three to over eighty.

Over the course of nine months, I studied multimodal content produced by ninety midlife and older women for their Instagram feeds, focusing particular attention on twenty-five of those women. Many of the women also maintain blogs, and in those cases, I studied the blog content as well. As part of my research process, I collected data on hashtag usage, recorded observations about practices and interactions, and identified common themes that emerged in posts and comments. In addition, I surveyed the women about their uses of Instagram and blogs and obtained completed questionnaires from twenty-one of the ninety women.

The Instagrammers I observed draw on a variety of semiotic resources as they construct identities and perform age on social media. Instagram and blog posts are "ensembles of modes, brought together to realise particular meanings" (Kress 115). These multimodal ensembles reveal "individual and group identities that are constructed through repeated performances of self and in anticipation of the expectations, social codes and discourses available within a given context" (Lewis 231). Digital literacies-knowledge, practices, and skills the women have developed through self-study and/or sponsorship (Brandt) - enable the multimodal performances I analyze in this article. Through their performances, the women render themselves visible "as part of the cultural mainstream" (Givskov and Deuze 401). Some use this visibility to push back against ageist stereotypes. Others pursue a range of other personal and professional goals. In all cases, the women's performances are situated within broader discourses on age and gender. Due to the epistemological complexity inherent in social media research and the opportunity this special issue provides to read age through multiple lenses, my work has been informed by a broad range of concepts from literacy, composition, media, gender, and age studies. I will examine some of these concepts prior to describing the methods and 
results of my research.

\section{Talking about Age}

Determining how to talk about age in this article posed an unexpected challenge. My research includes Instagrammers who are in their fifties, sixties, seventies, and eighties and focuses primarily on women who self-identify as over fifty (\#over50). After considering all possible options as well as associated critiques from age studies scholars (Cruikshank, 2013; Gullette, 2004), I chose to use over fifty as well as midlife and older adults. Older adults is the term recommended by the editors of this special issue and one adopted by many of the researchers whose works I consulted, but at what point do adults become older adults? Answers appear to vary from study to study, so older adults may refer to adults over age fifty or adults over sixty-five or even seventy-five. Similarly, midlife is used variously to refer to adults over age forty, adults in their fifties, and adults ages forty-five to sixty-five. I believe that my terminology_over fifty and midlife and older adults_is suitably flexible and inclusive.

\section{Age and Technology Use}

Even though popular media and advertisements "maintain the discourse that older adults are technology inept and digitally illiterate " (Schreurs, Quan-Haase, and Martin 361), research does not support this stereotype. In their study of older adults' digital skills and technology use, Eszter Hargittai and Kerry Dobransky remind us that many "older adults below 65 years of age . . . are still using the internet in their work life" and that "those 65-79, though many are retired, ... have experienced the diffusion of the online world into their daily work and home lives ..." (207). In light of the role technology plays in the work and home lives of so many older adults, it is not surprising that a 2017 Pew Research Center report on technology adoption trends finds older adults "moving towards more digitally connected lives" with $42 \%$ of American adults sixty-five and older "owning smartphones, up from just 18\% in 2013" (Anderson and Perrin 2). As I observed in my own research, growth in technology adoption is driven by "younger, relatively affluent and/or highly educated seniors" (Anderson and Perrin 3).

Regarding social media in particular, C. J. Hutto and colleagues report that among older adults, social media users tend to be younger seniors, female, educated with higher income, have higher confidence in technology and more positive attitudes of ICT, mostly access social media technology from their home computers, and typically desire to stay connected with family as their primary goal. (85)

Other motivations for social media use include "enjoyment, engaging in social contact, and to provide and receive social support" (Leist 381). According to the Pew Research Center, 64\% of Americans ages fifty to sixty-four and 37\% of Americans sixty-five and older use social media (Smith and Anderson 4). Although fewer adults ages sixty-five and above are on social media, researchers found that those who do use the platforms "tend to be highly active and engaged" (Anderson and 
Perrin 12).

Instagram, the platform featured in my study, is a social networking service that allows users to share photos and videos, follow other users, and comment on content. Instagram is less widely adopted by midlife and older adults than Facebook and YouTube, but statistics provide evidence of Instagram use across the life course. As of 2018, 21\% of American adults ages fifty to sixty-four and $10 \%$ of those over sixty-five use Instagram (Pew Research Center). Worldwide, as of January 2018, there were 33 million female users in the forty-five to fifty-four range; 13 million in the fifty-five to sixty-four range, and 8 million sixty-five and older (We Are Social/Hootsuite). Unfortunately, the reports I consulted do not distinguish between passive consumption (e.g., lurking, watching videos) and active participation (e.g., creating and publishing content, commenting on posts) when referring to "use." The fact that older adults are visiting these platforms does not contribute to our understanding of what they are doing there, and I find it problematic that midlife and older adults are not more visible as content contributors in research on social media use.

Information that focuses on generational characteristics or age cohort statistics provides valuable evidence of use but an ultimately incomplete perspective on how midlife and older adults use social media. As Cecilie Givskov and Mark Deuze argue, "diversity in lived experience of older people in the new media environment constitutes a blind spot in current research" (400). Because literature on age and technology use tends to collapse rather than highlight differences among individuals, one of my research goals was to maintain a focus on the literate practices of individual midlife and older women. For this reason, I employed a case study methodology in addition to conducting an anonymous survey and compiling disaggregated data on hashtag use and other trends.

\section{Age and Gender}

Age-related stereotypes came to my attention once again as I explored age studies literature and scholarship on visual representations of age and gender. I devote space here to perspectives on ageism and gender because they influenced my interpretative work and challenged me to assess my own assumptions and beliefs. This material also illuminates the ways in which cultural values exert pressure on individuals to conform to norms and standards. Margaret Syverson's ecological approach to literacy reminds us that we must take into account "the complex interrelationships in which ... writing [or, in the case of my research, multimodal content] is embedded" (6), and cultural values are very much a part of the that web of interrelationships.

In Learning to Be Old, Margaret Cruikshank writes, "People over forty are targets for an astonishing range of insults, including birthday card jibes" (139). In addition to being ridiculed in greeting cards, cartoons, advertisements, and jokes (see Gendron et al. and Gullette on ageism and micro-aggressions), older adults are often labeled "forgetful, frail, deaf, and helpless" or "irritable, boring, grumpy, weak, mournful, debilitated, and . . cognitively impaired” (Fawsitt and Setti 357; Coudin and Alexopoulous 516). Older adult women are subjected to additional derogatory labels like hag, biddy, or old bag, and as Cruikshank notes, they are often "reviled as grumpy, frumpy, sexless, and uninteresting" (141). 
Mutton dressed as lamb or other critiques are at the ready when midlife and older women defy expectations by, for example, dressing "young." At the same time, successful, active, or positive aging discourses-“new, more positive version[s] of later life" (Moody 68)_define success "as reaching one's potential, being productive, achieving individual accomplishment, and, for the elderly, exhibiting behaviors that resemble those of young people" (Pecchioni, Ota, and Sparks 172). Jenny Hockey and Allison James describe how successful aging emphasizes the "moral duty of the individual to adopt regimes of diet and exercise which will bring older people's appearance and lifestyles closer into line with younger ones, so differentiating themselves from 'the elderly' who are past saving" (71). Often, midlife and older adults who appear to have met this moral imperative are the most visible and celebrated. In the introduction to Aging Femininities, Josephine Dolan and Estella Tincknell refer to this as the "new visibility" of "graceful agers" (xi).

\section{"Mutton dressed as lamb or other critiques are at the ready when midlife and older women defy expectations by, for example, dressing 'young."}

The visibility or invisibility of midlife and older women is an important topic within the context of my research, one that the Instagrammers I studied

confront either explicitly or implicitly through their literate practices. A number of scholarly sources devote attention to visible representations and performances of aging and/or to some combination of age, gender, and in/visibility (Barrett, Raphael, and Gunderson; Fairhurst and Baines; Featherstone and Hepworth; Featherstone and Wernick; Hepworth; Hockey and James; Meagher; Woodward). Michelle Meagher's "Against the Invisibility of Old Age" provides a particularly helpful overview of feminist scholarship on the cultural invisibility of older women. In the conclusion of her article, Meagher, referring to the theories of Kathleen Woodward, writes, "in order to learn to look at old women in new ways, they need to be wrenched from . . cultural invisibility. Old women must become a part of our visual culture-present in popular visual culture and in art" (142). My research examines one of the ways in which midlife and older women are making themselves part of popular visual culture.

\section{Digital Literacies and Online Self-Representation}

Deborah Brandt and Katie Clinton define literate practices as "the socially regulated, recurrent, and patterned things that people do with literacy as well as the cultural significance they ascribe to those doings" (342). As Brandt and Clinton acknowledge, these practices typically develop in response to technological changes (352). Social media platforms like Instagram and associated genres (e.g., post, story) have emerged in response to technological developments that make new ways of communicating possible. As a social media researcher situated within literacy and composition studies, I am particularly interested in how individuals employ digital literacies to craft online personas and to connect and communicate with others. Media studies scholar Nancy Baym explains, "Our ability to construct an online self-representation-whether authentic, fanciful, or manipulative-is limited and enabled by the communicative tools, or affordances, a platform makes 
available and our skill at strategically managing them" (123-124). Similarly, Elizabeth Tomlinson notes, "the possibilities for self-representation and performative identities have multiplied, and the need for new digital literacies used to perform these identities continues proliferating" (163). In other words, online self-representation is predicated on digital literacies.

The term digital literacies refers to situated practices that occur in online contexts. Cynthia Selfe and Gail Hawisher, who use digital literacy and technological literacy interchangeably, offer this definition: "the practices involved in reading, writing, and exchanging information in online environments, as well as the values associated with such practices-cultural, social, political, and educational" (Selfe and Hawisher, Literate Lives 2). In addition to Selfe and Hawisher's helpful definition, I appreciate this succinct variation from Understanding Digital Literacies: "the practices of communicating, relating, thinking and 'being' associated with digital media" (Jones and Hafner 13). The practices I studied are indeed associated with ways of not only reading, writing, and communicating but also of connecting and being.

Within literacy and composition studies, limited research exists on the digital literacies of midlife and older women. Notable exceptions include Debra Journet's “Inventing Myself in Multimodality: Encouraging Senior Faculty to Use Digital Media," Linda Stewart's “Come on in! Stepping into DMAC to Become a Digital Media Dweller," Angela Crow's Aging Literacies, and Heidi McKee and Kristine Blair's “Older Adults and Community-Based Technological Literacy Programs," in which the authors reflect on learning to use multimodal technologies in writing faculty development and community settings. Other relevant scholarship includes Selfe and Hawisher's Literate Lives in the Information Age and Hawisher and Selfe's "Women and the Global Ecology of Digital Literacies." These sources address age as one element of "a complex set of related factors that shape, and are shaped by, people's use of computers as tools and environments for reading and composing" (Hawisher and Selfe, "Women" 208).

In addition to examining literature on women's digital literacies, I consulted sources on identity and social networks (Baym; Chau and Lee; Georgalou; Harris; Marwick; Schmidt), which provided insight into how individuals use the semiotic resources available on various platforms to construct identities and signal affiliation. From my perspective, research on digital literacies and online selfrepresentation intersects in productive ways with Margaret Gullette's work on age identities in Aged by Culture: "Age identity is a special subset of autobiography-which I understand broadly, as a narrative that anyone can tell about one's self, to self and others, whether informally in conversation or written for archival purposes" (124). Drawing on these and other sources, my research examines Instagram and blog content for evidence of how midlife and older women use digital literacies to exercise control over their online self-representations and to tell multimodal age identity stories. In keeping with this focus, my interpretive work is also informed by Gullette's claim that "where age is concerned, we both have a body and ... perform our body" (162), by Woodward's work on performing age, and by literacy and writing studies scholarship on performance and identity (Fishman et al.; Ivanič; Lillis; Love), which prompted me to consider how Instagrammers discursively construct their identities as they engage with the "the performativity of everyday life" (Love 13). 


\section{Methods}

My research focuses on a subpopulation of Instagram users: female lifestyle Instagrammers and bloggers who self-identify as being over fifty. Marketing agency Mediakix offers a helpful explanation of the lifestyle category: "A lifestyle blogger creates content inspired and curated from their personal interests and daily activities. As such, lifestyle blogs are oftentimes highly personalized to the author's location, life stage and experience." I identified this subpopulation while using Instagram's search feature to detect age-related hashtag trends. Many of the women within the subpopulation I studied use hashtags such as over 50 style (\#over50style) or advanced style (\#advancedstyle) to indicate affiliation with the over 50 (\#over50) lifestyle Instagrammer and blogger community. It is common for the women to include \#over50 or similar hashtags even if they are in their sixties or above. In keeping with this common practice within the subpopulation, I decided to use over fifty as the starting point for inclusion in the study. Although some of the women have a presence on multiple social media platforms, I chose to focus on the most content rich and widely used: Instagram and blogs. All of the blogs and feeds I studied are public rather than private.

Small data qualitative analysis approaches best support efforts to "understand specific phenomena as they exist among narrow subpopulations of Instagram users" (Laestadius 581). Therefore, I relied on a combination of qualitative approaches:

- unobtrusive observation of literate activities on Instagram and blogs (actions and interactions including posting, captioning, commenting, replying, hashtagging, and username tagging)

- $\quad$ analysis of extant data (multimodal content on Instagram and blogs; published interviews or other materials featuring the women)

- $\quad$ interpretation of elicited data (survey results)

Social media research poses well-documented ethical and methodological challenges. When planning my study, I consulted with my university's institutional review board (IRB) and carefully considered literature on the ethics of online and social media research (Eynon, Fry, and Schroeder; McKee and DeVoss; McKee and Porter; Salmons; Townsend and Wallace). Although the blogs and Instagram feeds I observed are public and of a non-sensitive nature, I decided to obtain consent from the women who are named and quoted in this article. As required by the IRB, I prefaced the anonymous online survey with an informed consent document, and my other observations rely on disaggregated data.

I identified ninety potential participants through their use of age-related hashtags as well as through Ari Seth Cohen's Advanced Style blog, which is devoted to showcasing "the sartorial savvy of the senior set" (Cohen). Although health and fitness are occasional topics on the feeds and blogs I studied, I did not recruit participants from what I perceive to be a separate subpopulation: fit over 50 (\#fitover50) Instagrammers whose content focuses almost exclusively on workouts and nutrition. In addition, I was not able to include exclusively foreign-language Instagrammers, even though some of them do use the over 50 (\#over50) hashtag.

Desiring to obtain as many women's perspectives as possible and with participants' convenience in mind, I employed an anonymous online survey as the most logistically feasible method of gathering 
information from a busy and geographically distributed group. I invited all ninety to participate in the survey, and twenty-one completed the questionnaire. As I gained a better sense of who among the ninety posted most actively and in order to balance breadth with depth, I began to focus on twentyfive women in particular who were representative of the heterogeneity I noticed among the broader subpopulation. Specifically, I observed English-speaking women from across the globe who range in age from their fifties to their eighties and who use Instagram and blogs for a variety of purposes. I invited ten of these women to be featured in case studies, and seven agreed. Due to space limitations, I include only four in this article. Each case represents an individual's unique personality, style, and motivations, while also illustrating key strategies I observed multiple women using to construct and communicate multimodal age identity narratives on social media.

\section{Discussion of Findings}

\section{Survey Results}

For the purposes of this article, I will focus on survey results that intersect with discourses on age and gender. The survey instrument I designed, however, was meant to solicit a broad range of information about how participants' literate practices on Instagram and blogs are shaped by literacy sponsors, learning opportunities, personal and cultural values, motivations and goals, platform affordances and limitations, and genre conventions. The questionnaire included the following four questions and invited participants to share additional information about their social media use as well:

1. Why do you use Instagram?

2. How did you learn to use Instagram?

3. Do other people influence how you use Instagram?

4. If you also maintain a blog, how did you get started and what are your goals for the blog? Although the survey invitation and consent document included information about the subject of

"Instagram can provide women with a space for playful, experimental identity work. The catalyst for this experimentation, however, may be a sense of anxiety or uncertainty about how to be "appropriate" as a woman over fifty." my research, I intentionally refrained from posing agerelated questions, leaving it up to the women to decide whether age was a topic they wanted to discuss in relation to their social media use.

Many respondents did choose to talk about age and aging, and they did so candidly. For example, one respondent wrote,

Part of me was wondering how am I to be now that I'm in my fifties. You know, how am I to look, what do I wear, is this appropriate for this age. ... I don't know why but [it] became a thing. Using Instagram allowed me to play with that idea of expression dressing and being comfortable with who I am. I started posting my results of playing in my closet and got great responses and comments. I also love giving encouragements and continuing conversations 
in the DMs [direct messaging]. I've make great connections because of it.

As this quote suggests, Instagram can provide women with a space for playful, experimental identity work. The catalyst for this experimentation, however, may be a sense of anxiety or uncertainty about how to be "appropriate" as a woman over fifty. This uncertainty is unsurprising, surrounded as we are throughout our lifetimes by age stereotypes, cultural norms and taboos about aging bodies, and media discourses that, on the one hand, extoll the virtues of pursuing an "ageless," youthful appearance and, on the other, admonish women over fifty who are perceived as failing to act or dress their age. As Julia Twigg notes in Fashion and Age, "the traditional cultural trope of 'mutton dressed as lamb' [is] still widely recognized and used as a term of control, policing women's appearance and disciplining their bodies ..." (16). Although I observed some of this policing on Instagram and blogs in the form of, for example, advice about what does or does not flatter an older woman's body or negative reactions to bared aging skin, it appears to be tempered by the influence of a "you do you" philosophy and a tendency to respond positively to unique styles when presented confidently.

If they reach an audience, women's age identity performances on Instagram are sanctioned (or, apparently more rarely, censured) by followers through Instagram's feedback mechanisms: likes, comments, and direct messaging. Survey respondents reported only positive experiences. For women who receive encouraging feedback and establish meaningful, supportive connections with followers, Instagram can feel empowering. Multiple women who participated in the survey use terms like "inspirational," "empowering," and "encouraging" to describe what they have experienced on the platform, and one respondent calls Instagram "a very positive and empowering community." As I will discuss in my case study analyses, the women whose practices I observed receive numerous, sometimes hundreds, of affirming comments on each post. Instagram's automatic comment moderation feature likely also contributes to the positive climate these women experience. As Instagram explains, "Comments that may be inappropriate, offensive or bullying are automatically filtered out from your posts and live videos."

Another respondent offers this perspective on how Instagram empowers midlife and older women: "Because Instagram is visual, many in the 50 and older are reluctant to start posting. But when they get connected with other[s] in the 50 and older genre they are learning a better perception of aging and this creates a new empowerment." While the mention of reluctance hints, once again, at the anxiety some women feel about aging and how "to be" over fifty, achieving visibility on Instagram and connecting with other visible midlife and older women enables "a better perception of aging."

Some of the women who participated in the survey actively aim "to encourage women of all ages" or "to inspire women over 50 and show that they are relevant." Another woman relates,

I started when I went gray and I realized that I was not represented anywhere in mainstream media-yet I am in the industry! So I decided to simply be a gray haired 'presence' and if nothing else would allow other silver haired women to see themselves represented. I keep learning and growing as I age and I aim to keep sharing that experience so the others feel less alone and marginalized.

This quotation makes the problem explicit: some midlife and older women feel "alone and marginalized.” As survey responses suggest, women over fifty may not see themselves adequately 
"represented" in "mainstream media," and they may feel irrelevant or unsure of their place in youthdominated popular visual culture, including, at least initially the visual culture of Instagram. As survey participants suggest, however, making themselves present and visible on Instagram enables midlife and older women to ensure representation, establish connections with members of a supportive community, inspire women of all ages, and promote positive perceptions of age and aging.

In addition to providing insight into their motivations and goals, survey respondents shared some of the values and beliefs that guide their practices on social media. These were particularly evident in responses to the question about influences. In their answers, numerous participants chose to emphasize the importance of remaining "independent" and "individual" and of being "authentic" and one's "own woman." These values align with well-known cultural values, such as the emphasis on independence and individuality in the United States, and they are often associated with the "baby boomer" generation in the popular imagination. Authenticity, realness, and originality are also valued on social media specifically, where it pays to stand out and where followers may be turned off by, for example, paid content that does not seem true to the poster's established persona. In my case study analyses, I examine authenticity and individuality as values evident in the Instagrammers' discursively constructed identity performances.

\section{Case Studies}

I present as case studies four women who demonstrate various ways midlife and older women use Instagram to achieve visibility. ${ }^{1}$ The motivations revealed by the survey are evident here, as the women use digital literacies and the affordances of Instagram to connect, inspire, promote, have fun, and express themselves. Amber Buck has demonstrated that "[s]elf-presentation on social network sites happens ... through the construction of profiles, and through interactions with other social network site users" (15). I include attention to profiles and interactions while also examining selfrepresentation strategies evident within the visual and textual content of feeds and posts. My analysis is guided by Nancy Baym's identity cue categories: "personal identity cues" and "social identity cues" (108-19). An individual's literate actions online provide personal identity cues: writing a user profile, posting a profile picture, commenting on other users' posts, replying to comments, selecting hashtags, and so forth. Social identity cues include "public displays of connection" (Donath and boyd 71), such as followers, likes, comments left by followers, and hashtags that signal group affiliation.

\section{Case Study 1: Jeanie Marsh, Jeamada, The Invisibility Myth, and Goldie Magazine}

I first came across Jeanie Marsh-Dawson, the subject of my first case study, in Instagram photos tagged not dead yet (\#notdeadyet) and the invisibility myth (\#theinvisibilitymyth), which is also the name of her blog. In her Instagram profile, Marsh-Dawson describes herself as an "Insatiably curious 61 yr old adventurer of the heart \& mind, with an attitude of No Limits" (Fig. 1).

Her approach to the lifestyle genre emphasizes "personal interests and daily activities" (Mediakix) rather than focusing primarily on fashion and beauty. Her feed features photographs from her travels and everyday life, including various images of objects, places, and people. Image captions are sometimes straightforward and sometimes characterized by humor, sarcasm, or anti- 
ageism sentiments. In a March 2018 Instagram post, Marsh-Dawson wears a tiara and a bright pink blouse, hands crossed over her chest to reveal a tattoo and ornate bangle. The caption adds meaning and provides a context for the image, taking to task an actress who "says that at 52 she has started to
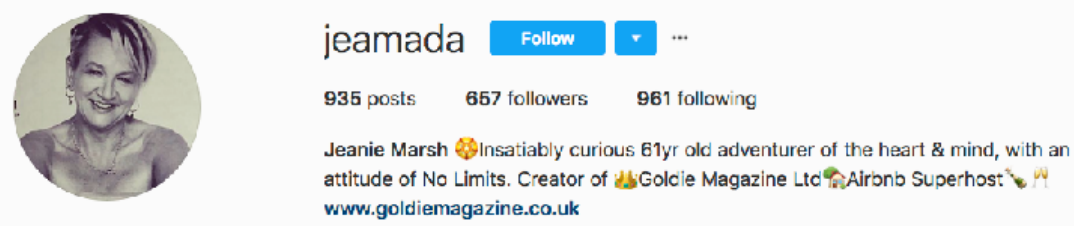

Fig. 1. Instagram profile for Jeamada (@jeamada), Jeanie Marsh-Dawson, 2018.

feel 'invisible and irrelevant' now a new generation is commanding the spotlight.' Well boo flipping hoo - get over yourself. ... Put on your tiara \& deal with it woman囚 \#keepitreal \#ageless \#notinvisible \#notdeadyet \#getoverit \# 1stworldproblems \#makesmemad \#behappy \#smile \#theinvisibilitymyth.” A conversation emerges as comments from followers support and elaborate on Marsh-Dawson's statement and as she replies to those comments. As is the case with the other women I observed, Marsh-Dawson draws on a combination of semiotic resources to make meaning and engage an audience on Instagram, and her feed is filled with personal and social identity cues.
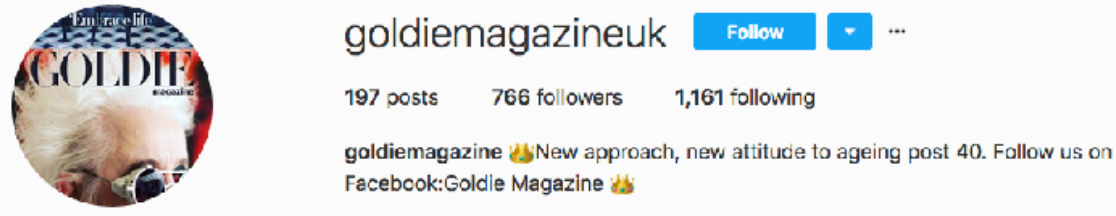

Fig. 2. Instagram profile for Goldie Magazine (@goldiemagazineuk), Jeanie Marsh-Dawson, et al., 2018.

Marsh-Dawson's July 31, 2017, post on her The Invisibility Myth blog presents an argument that connects social media, community, in/visibility, and positive aging. She writes,

This world needs hashtags like: livefastdieold, advantageofage, notdeadyet, ageingcanbefun, the invisibilitymyth. With the challenges that we face as we grow older, we need this diverse, inclusive global community network of our own, with [its] shared ethos of supporting each other whilst endeavouring to live our individual lives to the fullest. . . This highly visible, glorious movement is not just colourful, entertaining fun, it's also about connectivity, community and support, so I say it again: Fuck Invisibility!

Marsh-Dawson's manifesto rejects the idea that to age is to become invisible within society (the invisibility myth), offering an alternative vision and a strategy for how social media can provide "connectivity, community and support." Her other project, Goldie Magazine (Fig. 2) began as an 
Instagram feed (@goldiemagazineuk) prior to the launch of the print version in April 2018. The Goldie Magazine feed enacted the strategic vision voiced in Marsh-Dawson's blog post through a " 3 words on ageing" campaign that can be read as a form of anti-ageism activism designed to make midlife and older adults more visible on Instagram while promoting age-positive messages. Goldie Magazine invited followers to DM (direct message) their " 3 words" to be featured, along with their photographs, on Goldie's feed. The result is a diverse collection of images and perspectives on age and aging.

\section{Case Study 2: Silvana Stefonovic-Riley, Embellish or Perish}

Survey respondents emphasized inspiration, personal expression and enjoyment, and making connections as reasons for using Instagram, and my second case study provides an example of the influence of these goals and motivations. In her Instagram profile, Silvana Stefonovic-Riley (@ embellish_or_perish) describes herself as "Australian. Embellished. Visible. Self discoverer. Traveller. Photo snapper. Story teller. Friends gather. Muse. Model. Making my life art” (Fig. 3). StefonovicRiley's feed features original content as well as other material, such as reposted content from other creators that she tags inspiration (\#inspiration). Her original content includes digital art created with Photo Lab, photographs taken by and sometimes with others, brief videos, and photographs she has taken of herself (selfies) showcasing her "embellished" signature style.
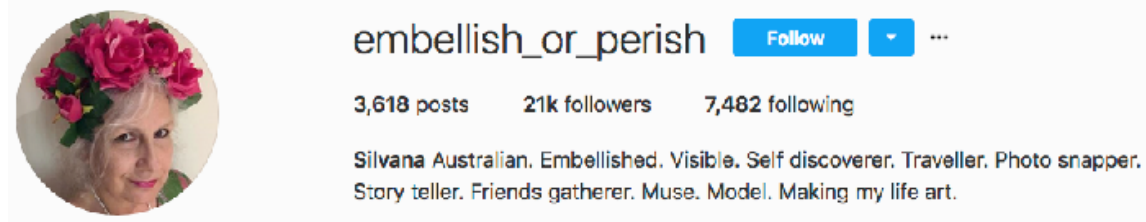

Fig. 3. Instagram profile for Embellish or Perish (@embellish_or_perish), Silvana Stefonovic-Riley, 2018.

Stefonovic-Riley, who tags herself the queen of selfies (\#thequeenofselfies), uses the genre as a playful but powerful tool for self-representation and achieving visibility. Martin Hand recognizes selfies as "visual self-expression for consumption by others" (224), and in "From Narrating the Self to Posting Self(ies)," Alexandra Georgakopoulou treats "selfies as small stories," a perspective that "recognizes narrative stancetaking as an important aspect of posting selfies in context and for specific viewers/users. Storying in selfies is thus viewed as a dynamic, contextually emergent process co-constructed by selfie-posters and users that engage with them ..." (302-303). Building on some of the themes uncovered in the survey, selfies not only serve as a form of self-expression but also reflect other motivations, including the desire to connect and inspire. Followers engage with the selfies, as well as other forms of content, by liking and commenting on them. Comments generally draw attention to specific features of the image and/or offer greetings or compliments. They often also include emojis, icons that range from decorative to emotive. 
Stefonovic-Riley draws on multiple semiotic resources to make meaning in her posts:

- Visual content: images, photographs, videos, and emojis like 5

- Descriptive image captions (the main textual element associated with Instagram posts), which range from something as simple as "Get up from last week" to a 385-word caption about a family gathering

- Hashtags, as exemplified by this list from an April 17, 2018, post, which includes a mix of personal identity cues (e.g., \#makinglifeart, \#selfiequeen) and social identity cues (e.g., \#aussiestyletribe, \#advancedstyle):

\#embellish_or_perish \#advancedstylegoddess \#makinglifeart \#1withmyart \#advancedstyle \#advancedstyledownunder \#aussiestyle \#aussiestyletribe \#fabover50 \#styleover50 \#styleoverfifty \#50plusstyle \#mystyle \#fiftyplusstyle \#fiftyplusandfabulous \#50plusandfabulous \#selfie \#selfiequeen \#theselfiequeen \#queenofselfies \#pinkhair \#thequeenofselfies \#silvana \#silvana_stefanovic_riley

- $\quad$ Responses to followers' comments

As her profile highlights, Stefonovic-Riley prioritizes visibility and friend gathering, goals which are shared by many of the women in the Instagram subpopulation I studied. The Embellish or Perish feed demonstrates mechanisms for pursuing these goals. For example, visibility can be achieved by posting frequently, sharing images of oneself, using descriptive tags to signal affiliation and ensure that one's content will appear in keyword searches, and by being a "friend gatherer" who actively and enthusiastically responds to commenters.

Additionally, the gaze in a photograph can be a "significant semiotic resource" (Veum and Undrum 95). Even when wearing sunglasses, Stefonovic-Riley often angles her face so she is looking directly at the camera. According to Aslaug Veum and Linda Undrum, “The gaze ... indicates whether the viewer is encouraged to engage with the represented person or not. When the represented person gazes directly at the viewer, an imaginary contact is established" (95). Thus, "the act of making and publishing selfies is not only an act of self-presentation, but also an invitation to interact. Through the direct gaze, the selfie maker suggests that she is eliciting some kind of response from the viewer" (95). Thus, Stefonovic-Riley demonstrates openness and approachability through images as well as words, further contributing to her goal of friend gathering.

Stefonovic-Riley engages to some extent with age-related issues and assumptions. The keyword visible in Stefonovic-Riley's profile description suggests that her use of Instagram intersects with broader conversations about gender, age, and representation, and she references age occasionally, mentioning, for example, acquiring a senior travel card and turning "the fabulous 61." She also engages with discourses on aging when, for example, she pokes fun at a newspaper article categorizing people as middle-aged based on their top ten worries and their favorite music, movies, and television shows: "Well it's official, I am middle aged and all because I like Queen. That is surprising, as in the absence of any other signs of middle age, I would not have known" (May 28, 2018). In contrast to Marsh-Dawson's more overt anti-ageism stance, Stefonovic-Riley tends to dismiss age stereotyping with humor.

Embellish or Perish emphasizes experimentation and creativity while encouraging viewers to see 
life as an ongoing journey of self-discovery. In keeping with standard approaches to self-branding on social media, Stefonovic-Riley maintains stylistic and thematic consistency on her feed. On the other hand, her content emphasizes the extent to which she embraces change. For example, in a series of posts from March 2018, she shares photographs of what she wore in her "civilian work days before [she] started to wear whatever [she likes]." "All I know," Stefonovic-Riley writes, "is I am no longer her" Rather than experiencing this shift as destabilizing, she appears to have found it liberating. Having recently dyed her silver hair pink, Stefonovic-Riley writes, "change is as good as a holiday" (July 8, 2018).

The Embellish or Perish feed promotes a positive version of later life without glossing over the fact that grief, doubt, and "tribulations" are also part of the journey. Stefonovic-Riley appears to delight in beauty and possibility, and her Instagram age identity story celebrates change, creativity, individuality, friendship, and family. Employing digital literacies in pursuit of the goals and interests described in her profile and using available semiotic resources to suit her own purposes and style, Stefonovic-Riley demonstrates one approach to being present in popular visual culture.

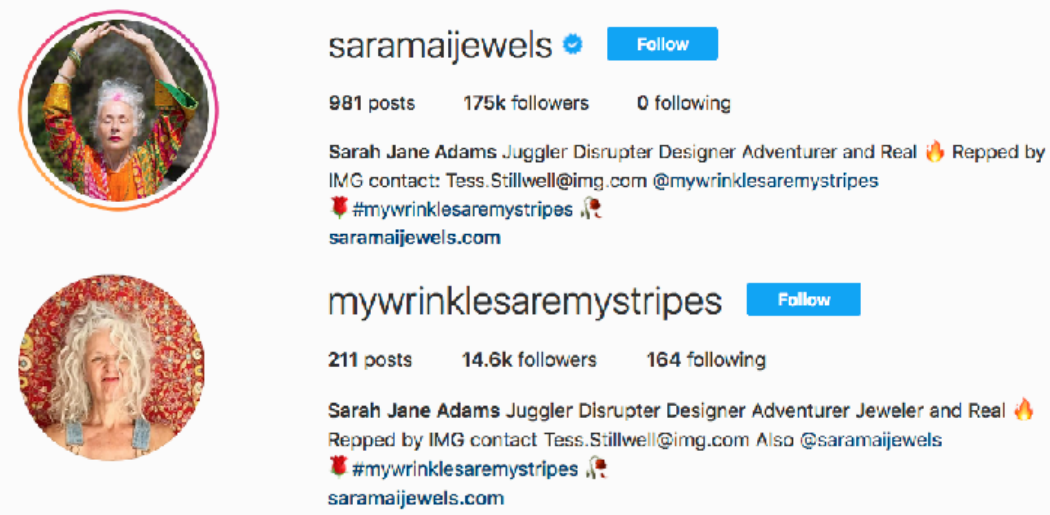

Fig. 4. Instagram profiles for Saramai Jewels (@saramaijewels) and My Wrinkles Are My Stripes (@ mywrinklesaremystripes), Sarah Jane Adams, 2018.

Case Study 3: Sarah Jane Adams, Saramai Jewels and My Wrinkles Are My Stripes

My third case study focuses on Sarah Jane Adams, a self-described "Juggler Disrupter Designer Adventurer Jeweler" who, through somewhat serendipitous circumstances but largely because her style and attitude resonate with such a broad range of people, has achieved a remarkable level of visibility on Instagram as well as in the media. Adams maintains two public Instagram accounts. Although there is some overlap between the two, she tends to offer glimpses into her daily life on mywrinklesaremystripes (e.g., family photos, photos and videos she captures of everyday objects and scenes) and uses saramaijewels to feature her professional work and brand collaborations (e.g., Priceline Pharmacy, 7 for All Mankind, Mercedes).

With over 175,000 followers on her saramaijewels account, Adams's age identity performances reach a broad audience. Like Stefonovic-Riley, Adams has been featured in Ari Seth Cohen's Advanced 
Style projects, and on the Advanced Style blog she explains that she created the My Wrinkles Are My Stripes hashtag (\#mywrinklesaremystripes) after a saleswoman offered a sample of a wrinkle removing cream: "My wrinkles do not scare me; they show me and therefore my experience. Hopefully there is a little wisdom which comes with these stripes. I see them as a badge of honour and a mark of roads travelled and experiences had. Why would I not be proud and happy to show them?" Adams ends her story with words of encouragement for other women: "Accept your true self, love your true self, smile and laugh often, gather those laughter lines and creases which come when you share a joke. They are you. The world needs to see more of YOU." The theme of acceptance carries over to Adams's Instagram feeds, particularly when she engages in self-reflection about aging:

- $\quad$ "I accept my wrinkles; my face is my story and is unique" (July 6, 2017).

- "This body was birthed 62 years ago today. I accept that I have had longer time within this vessel than I have remaining, and I give thanks for each day" (April 15, 2017).

- “. . . with gratitude, grace and acceptance, I intend to look after [my body], challenge it, stretch it, explore with it, to [its] maximum potential" (March 2, 2017).

An acceptance-oriented attitude toward aging counters what Adams recognizes as the "toxic" antiaging messaging so prevalent in marketing targeted at women. Critics may argue that her case is an example of the "new visibility" of "graceful agers" (Dolan and Tincknell xi) and that it is easy for the fit and active Adams - widely perceived as attractive by followers - to practice and preach acceptance. From my perspective, however, Adams uses her visibility on Instagram to actively challenge assumptions and question reactions. As she suggests in a March 10, 2017 post that references selfacceptance in a hashtag (\#selfacceptance), "An unfilled, unpulled, uninjected, unpeeled, unaltered, 61 year old female face appearing on your screen is a small act of rebellion."

Adams engages discourses on age and gender in a variety of ways, including reappropriation of terminology. For example, on mywrinklesaremystripes she captions a photograph of herself walking next to a bird mural. “This old bird is migrating to warmer climes ...” (@mywrinklesaremystripes, July 10, 2018). On her saramaijewels feed, she captions a photograph of herself standing next to a woven tote "Two Old Bags" and labels the image with hashtags including \#oldbag, \#mywrinklesaremystripes, and \#keepingitreal (May 4, 2017). Adams often uses hashtags to layer meaning onto an image rather than to signal affiliation. The "keeping it real" (\#keepingitreal) hashtag reflects Adams's commitment to openness and authenticity and plays a particularly significant role in the way she uses her feeds for cultural critique.

Two additional examples of "keeping it real" illustrate Adams's approaches to multimodal age identity storytelling and cultural critique. A May 17, 2016, post on saramaijewels shows Adams topless with a hat across her chest. On July 29, a less closely cropped version of the image reveals her midriff, which she describes using the hashtags baby belly (\#babybelly), twin belly (\#twinbelly), stretchmarks (\#stretchmarks), and 61 (\#61). In the caption, she explains, "Keeping it real means showing the out takes."

Adams employed a similar strategy in a series of December 2016 posts on saramaijewels. On December 22, she posted a photograph of herself in a red bathing suit. Viewers commented, "sexy," "hawt," "stunning," "true beauty, "fine," "beautiful." Four days later Adams posted a photo of her 
midriff captioned, "This is what's underneath the red swimsuit. So, you tell me. What do you really think now?" (December 26, 2016). As in the previous example, hashtags label the image and guide interpretation: twin belly (\#twinbelly), baby belly (\#babybelly), keep it real (\#keepitreal), stretchmarks (\#stretchmarks), throwing down the gauntlet (\#throwingdownthegauntlet). As of June 28, 2018, Adams's question had prompted 224 responses. While one or two commenters express revulsion, the vast majority share reactions ranging from admiration to gratitude. Some women voice a sense of relief upon seeing they are not alone in their perceived imperfections.

"What [Adams] accomplishes on a platform characterized to some extent by the fetishization of women's bodies and the idolization of beauty, youth, and celebrity, makes her visibility on Instagram more than a 'small act of rebellion."'

Adams's multimodal age identity storytelling suggests that age is "irrelevant" (April 24, 2017), at least when it comes to a woman's core self and personal style. Through this storytelling, she also demonstrates an approach to aging based on self-acceptance, rejection of taboos, and "keeping it real." As a selfdescribed "disrupter," Adams's Instagram practices call to mind performance art. She offers representations of herself for public consumption, using her own body to elicit reactions and then prompt critical examination of those reactions. What she accomplishes on a platform characterized to some extent by the fetishization of women's bodies and the idolization of beauty, youth, and celebrity, makes her visibility on Instagram more than a "small act of rebellion."

Case Study 4: Beth Djalali, Style at a Certain Age

My final case study represents a key trend revealed in survey results: midlife and older women are not only using Instagram to express themselves and connect with others; some of them have made content creation into a career. Beth Djalai, a professional lifestyle blogger, maintains a blog, Instagram feed, and YouTube channel, as well as Facebook and Pinterest pages, all united under the brand name Style at a Certain Age. Her Instagram profile features her brand logo rather than a photograph and lists her motto: "trends come and go but true style is ageless." Over half the women who responded to my survey report using Instagram for promotion and marketing, and a number, like Djalali, have turned social media content creation into a career.

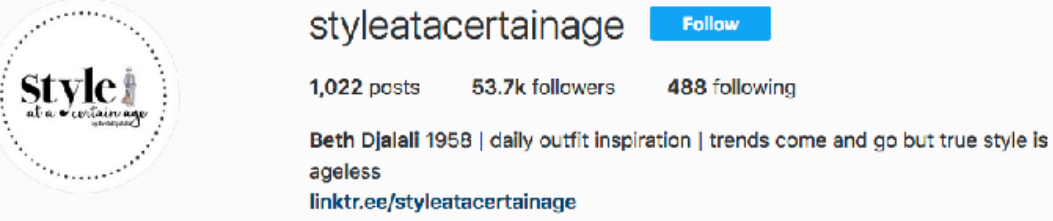

Fig. 5. Instagram profile for Style at a Certain Age (@styleatacertainage), Beth Djalali, 2018.

The "bio" page of Djalai's Style at a Certain Age blog features a portrait of her at age thirty-two, 
which she explains along with the purpose of blog in this way:

Needless to say, if you've stopped by my blog, you know I have an interest in fashion. This photo was taken of me at age 32, and while some things have changed since then I'm still just a girl at heart navigating through her personal style. My hope with this blog is to encourage other women to embrace their own personal style as well. Because one thing I've learned is that when you look great, you feel great and you step out the door armed with confidence! While age studies scholars may take issue with Djalai's use of the terms "ageless" and "a girl at heart," she, like all of the women I studied, tells her age identity story in the manner she chooses and achieves visibility on her own terms. Djalai has used her approach to gain over 50,000 followers on Instagram, so her content clearly resonates with her target audience, which likely includes other lifestyle Instagrammers as well as women like the one in my survey who are questioning how to be and look over fifty.

The Style at a Certain Age blog includes style, beauty, lifestyle, fitness content categories and a link that allows followers to shop her looks (purchase items featured in

"Although reports on social media tend to focus on youth, research on age and technology use, as well as common sense, tells us that midlife and older women are present and active on social media for a variety of personal and professional reasons." her outfit of the day posts). Photos on the blog and Instagram feed showcase Djalali's classic style and feature her posing in a variety of mainly outdoor settings. Unlike candid personal shots and selfies, the photographer's gaze plays a mediating role. Djalali's photographer is her husband: "Since his retirement, my husband has followed his love of photography and opened a small shop named Makbeth Studio. Now, when it is photo time for me, my husband is the one behind the lens" (Djalali, "Who"). The photographs are the result of a creative partnership, and Djalali exercises control over her self-presentation as she maintains personal style and brand consistency. Consistency is also maintained by using a signature writing style characterized by lack of capitalization and a peppy, conversational tone created by simple syntax, multiple exclamatory sentences, and a playful diction: "take a look at this straw handbag i've had for ages. it's a complementary shade of orange that gives this ootd a nice zing. when the temps heat up, i'm the first one to grab a wicker or straw handbag. don't they just scream summer?!” (Djalali, “Garanimal”).

Figure 6 shows a popular Style at a Certain Age Instagram post that participates in a crossplatform social media trend: Throwback Thursday. While some users post decades-old photographs of themselves, Djalali uses Throwback Thursday as an opportunity to feature some of her past outfits, usually connecting them thematically or by color. Djalali encourages engagement by inviting followers to vote for their favorite photo and share what they "like best about Style at a Certain Age." She not only invites but consistently responds to follower comments. Personal and social identity cues are visible in the list of hashtags associated with the Throwback Thursday post (Fig. 6), which show Djalali promoting as well as connecting.

Although reports on social media tend to focus on youth, research on age and technology use, as well as common sense, tells us that midlife and older women are present and active on social 
media for a variety of personal and professional reasons. As my survey results reveal, women who post lifestyle-related content to Instagram and blogs often employ digital literacies in the service of promoting themselves as professionals. In other instances, as Djalali's case demonstrates, they have launched new careers as professional lifestyle bloggers and social media content creators.
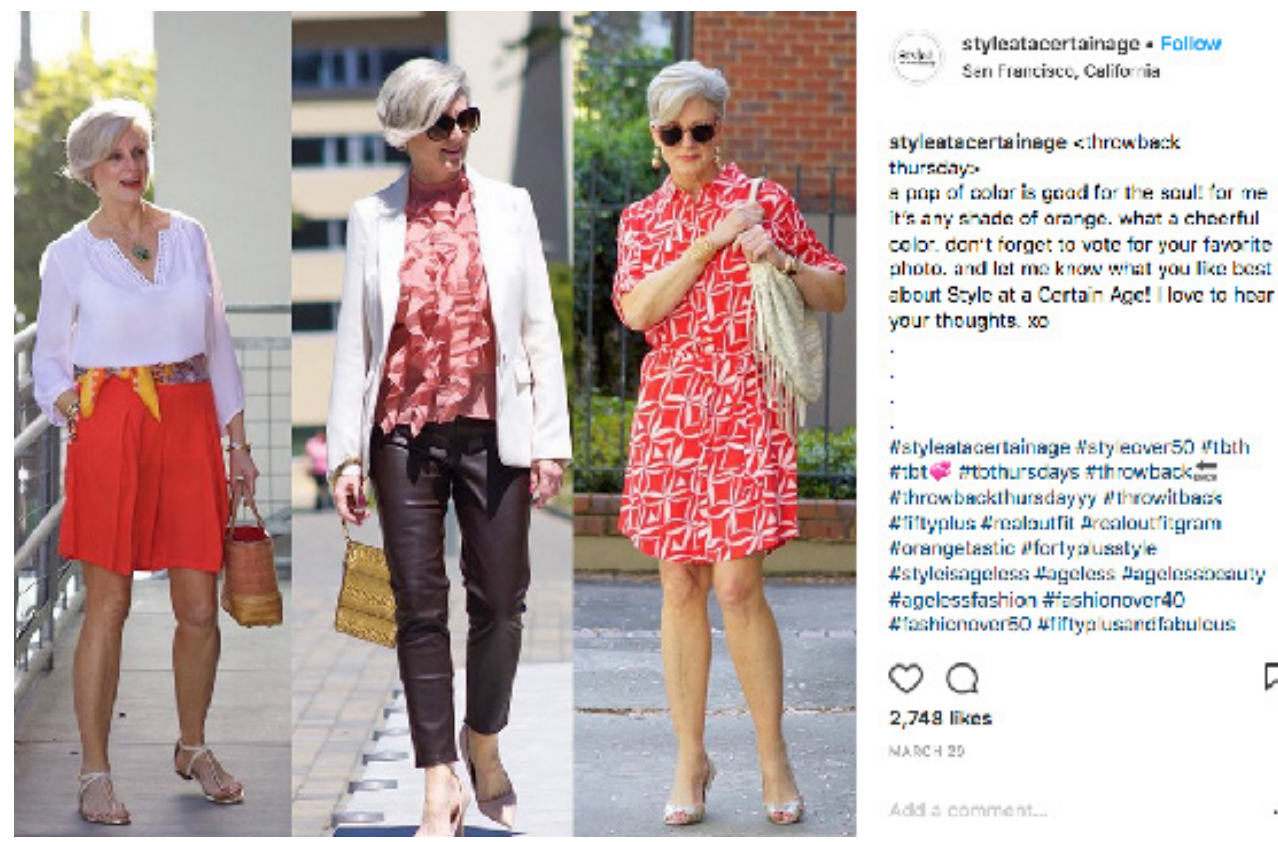
photo. and let me $k$ now what you like best about Szyle at a Certain Age! | love to hoor your thoughts. $\mathrm{xo}$

Histyleatacertainage Issty ecver 50 Hibth nitbt At ihrowbackthuradayy th thoutbats L'it'yplus: A' cedlautfit arcolout'itgram forangetastic afcrtyousatye H'styleisageless thgeless Hagelessosaty" \#agelessfashion \#̈:shionover40 t"ashicnoverso Hfiftya usentiatal cus

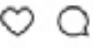

2,749 likes

$\mathrm{N} \times \mathrm{BC}+2 \mathrm{2}$

Fig. 6. “Throwback Thursday” Instagram post. Source: (CBeth Djalali, Style at a Certain Age, 2018. Used with permission.

\section{Conclusion}

This study contributes valuable new knowledge about the motivations, goals, and literate practices of midlife and older adults on social media, revealing some of the strategies \#over50 women use to "story" or "discursively construct themselves" (Georgalou 24) on Instagram and blogs. Whereas most existing scholarship on visual depictions of age focuses on images that are controlled by other people (e.g., advertisers, community groups), I show how \#over50 lifestyle Instagrammers and bloggers control their self-representations. As with all literate practices, these women's self-representationstheir multimodal performances of identity-mean and do something within a complex web of social practices, discourses on age and gender, offline experiences and relationships, professional goals, personal needs and aspirations, cultural values and assumptions, mediating technologies, and so forth. All of these influences are at work as midlife and older women engage digital literacies in the service of self-expression, inspiration, connection, and promotion.

The multimodal performances of self I studied are complex, playful, experimental, and sometimes provocative. While not glossing over topics like menopause, grief, and health concerns, 
they challenge negative age stereotypes and encourage viewers to "learn to look at [older] women in new ways" (Meagher 142). As I observed, these performances attract the attention of other women over fifty who are seeking inspiration, representation, and connection as they engage in their own age-related identity work. Younger Instagram users provide another audience for the performances, glimpsing in them possible future selves. Brands, marketers, magazines, and news outlets are also paying attention, which in turn increases the presence of midlife and older women in popular visual culture beyond Instagram. 


\section{Notes}

${ }^{1}$ I did not receive permission from all of the women I wanted to feature as case studies. Consequently, the stories of midlife and older women of color are unfortunately absent from this article, even though they are present on social media and were included in the survey. Those seeking insight into the social media practices of women of color may find Keisha Edwards Tassie and Sonja M. Brown's edited collection Women of Color and Social Media Multitasking: Blogs, Timelines, Feeds, and Community helpful, particularly Kandace Harris' "'Follow Me on Instagram': 'Best Self' Identity Construction and Gaze through Hashtag Activism and Selfie Self-Love." 


\section{Works Cited}

Adams, Sarah Jane. @mywrinklesaremystripes. Instagram.n.d. Web. 10 July 2018.

---.@saramaijewels. Instagram.n.d. Web. 10 July 2018.

---. "My Wrinkles Are My Stripes." Advanced Style. Ed. Ari Seth Cohen. 20 Mar. 2015. Web. 5 May 2018.

Amicucci, Ann N. "Rhetorical Choices in Facebook Discourse: Constructing Voice and Persona." Computers and Composition 44 (2017): 36-51. Web. 10 Apr. 2018.

Anderson, Monica, and Andrew Perrin. “Tech Adoption Climbs Among Older Adults." Pew Research Center: Internet \& Technology. Pew Research Center, 17 May 2017. Web. 10 Apr. 2018.

Barrett, Anne E., Alexandra Raphael, and Justine Gunderson. "Reflections of Old Age, Constructions of Aging Selves." Aging, Media, and Culture. Eds. C. Lee Harrington, Denise D. Bielby, and Anthony R. Bardo. Lanham: Lexington, 2014. 37-46. Print.

Baym, Nancy. Personal Connections in the Digital Age. Cambridge: Polity, 2010. Print.

boyd, danah. It's Complicated: The Social Lives of Networked Teens. New Haven: Yale UP, 2014. Print.

Brandt, Deborah. "Sponsors of Literacy." College Composition and Communication 49.2 (1998): 165 85. Print.

Brandt, Deborah, and Katie Clinton. "Limits of the Local: Expanding Perspectives on Literacy as Social Practice." Journal of Literacy Research 34.3 (2002) 337-56. Web . 14 May 2018.

Buck, Amber. "Examining Digital Literacy Practices on Social Network Sites." Research in the Teaching of English 47.1 (2012): 9-38. Web. 10 Apr. 2018.

Chau, Dennis, and Carmen Lee. "Discursive Construction of Identities in a Social NetworkEducational Space: Insights from an Undergraduate Facebook Group for a Linguistics Course." Discourse, Context \& Media 18 (2017): 31-39. Web . 14 May 2018.

Cohen, Ari Seth. Advanced Style. Blog. n.d. Web. 10 Apr. 2018.

Coudin, Genevieve, and Theodore Alexopolous. "Help Me? I'm Old?' How Negative Aging Stereotypes Create Dependency Among Older Adults." Aging and Mental Health 14.5 (2010): 516-23. Web . 14 May 2018.

Crow, Angela. Aging Literacies: Training and Development Challenges for Faculty. Cresskill: Hampton P, 2006. Print.

Cruikshank, Margaret. Learning to Be Old: Gender, Culture, and Aging. $2^{\text {nd }}$ ed. Lanham: Rowman \& Littlefield, 2009. Print.

Djalali, Beth. @styleatacertainage. Instagram.n.d. Web. 10 Apr. 2018.

---. "Bio." Style at a Certain Age. Blog. n.d. Web. 10 Apr. 2018.

---. “Garanimal." Style at a Certain Age. Blog. n.d. Web. 12 May 2018.

---. “Who Takes All These Marvelous Photos?” Style at a Certain Age. Blog. n.d. Web. 25 Apr. 2018.

Dolan, Josephine, and Estella Tincknell, eds. Aging Femininities: Troubling Representations. Newcastle upon Tyne: Cambridge Scholars, 2012. Print.

Donath, Judith, and danah boyd. "Public Displays of Connection." BT Technology Journal 22.4 (2004): 71-82. Web. 10 Apr. 2018.

Eynon, Rebecca, Jenny Fry, and Ralph Schroeder. "The Ethics of Online Research." The SAGE Handbook of Online Research Methods. Eds. Nigel G. Fielding, Raymond M. Lee, and Grant Blank, 2017. 47-72. Print.

Fairhurst, Eileen, and Sue Baines. "Exploring Positive Images of Ageing: The Production of Calendars." Valuing Older People: A Humanist Approach to Ageing. Eds. Ricca Edmondson and Hans-Joachim von Kondratowitz. Bristol: Policy P, 2009. 277-82. Print.

Fawsitt, Feargus, and Annalisa Setti. "Extending the Stereotype Embodiment Model: A Targeted Review." Translational Issues in Psychological Science 3.4 (2017). 357-69. Web. 10 Apr. 2018. 
Featherstone, Mike, and Andrew Wernick. "Introduction." Images of Aging: Cultural Representations of Later Life. Eds. Mike Featherstone and Andrew Wernick. New York: Routledge, 1995. 1-14. Print.

Featherstone, Mike, and Mike Hepworth. "Images of Positive Aging: A Case Study of Retirement Choice Magazine." Images of Aging: Cultural Representations of Later Life. Eds. Mike Featherstone and Andrew Wernick. Oxfordshire: Taylor \& Francis, 1995. 27-46. Print.

Fishman, Jenn, Andrea Lunsford, Beth McGregor, and Mark Otuteye. "Performing Writing, Performing Literacy." College Composition and Communication 57.2 (2005): 224-52. Web. 10 Apr. 2018.

Gendron, Tracey, et al. "The Language of Ageism: Why We Need to Use Words Carefully." The Gerontologist 56.6 (2016): 997-1006. Web. 10 Apr. 2018.

Georgakopoulou, Alexandra. "From Narrating the Self to Posting Self(ies): A Small Stories Approach to Selfies." Open Linguistics 2 (2016): 300-17. Web. 10 Apr. 2018.

Georgalou, Mariza. "Beyond the Timeline: Constructing Time and Age Identities on Facebook." Discourse, Context \& Media 9 (2015): 24-33. Web . 14 May 2018.

Givskov, Cecilie, and Marke Deuze. "Researching New Media and Social Diversity in Later Life." New Media \& Society 20.1 (2018): 399-412. Web. 10 Apr. 2018.

Gullette, Margaret Morganroth. Aged by Culture. Chicago: U of Chicago P, 2004. Print.

Hand, Martin. "Visuality in Social Media: Researching Images, Circulations and Practices." The SAGE Handbook of Social Media Research Methods. Eds. Luke Sloan and Anabel QuanHaase. Los Angeles: SAGE, 2017. 215-28. Print.

Hargittai, Eszter, and Kerry Dobransky. "Old Dogs, New Clicks: Digital Inequality in Skills and Uses Among Older Adults." Canadian Journal of Communication 42.2 (2017): 195-212. Web. 10 Apr. 2018.

Harris, Kandace L. “'Follow Me on Instagram' 'Best Self’ Identity Construction and Gaze Through Hashtag Activism and Selfie Self-Love.” Women of Color and Social Media Multitasking: Blogs, Timelines, Feeds, and Community. Eds. Keisha Edwards Tassie and Sonja M. Brown Givens. Lanham: Lexington, 2015. 131-43. Print.

Hawisher, Gail, and Cynthia Selfe. "Women and the Global Ecology of Digital Literacies." Women and Literacy: Local and Global Inquiries for a New Century. Eds. Beth Daniell and Peter Mortensen. New York: Lawrence Erlbaum, 2007. 207-28. Print.

Hepworth, Mike. "Images of Old Age." Handbook of Communication and Aging Research. Eds. Jon F. Nussbaum and Justine Coupland. New York: Erlbaum, 2004. 3-29. Print.

Hockey, Jenny, and Allison James. Social Identities Across the Life Course. New York: Palgrave Macmillan, 2003. Print.

Hutto, C. J., et al. "Social Media Gerontology: Understanding Social Media Usage Among Older Adults." Web Intelligence 13.1 (2015): 69-87. Web. 10 Apr. 2018.

Instagram. "How Do I Filter Out Comments I Don't Want to Appear on my Posts?" Instagram Help Center. n.d. Web. 2 July 2018.

Ito, Mizuko, et al. Hanging Out, Messing Around, and Geeking Out: Kids Living and Learning with New Media. Cambridge: MIT P, 2009. Print.

Ivanič, Roz. Writing and Identity: The Discoursal Construction of Identity in Academic Writing. Philadelphia: John Benjamins, 1998. Print.

Jones, Rodney H., and Christoph A. Hafner. Understanding Digital Literacies: A Practical Introduction. New York: Routledge, 2012. Print.

Journet, Debra. "Inventing Myself in Multimodality: Encouraging Senior Faculty to Use Digital Media." Computers and Composition 24.2 (2007): 107-20. Web. 5 May 2018. 
Kress, Gunther. Literacy in the New Media Age. New York: Routledge, 2003. Print.

Laestadius, Linnea. "Instagram." The SAGE Handbook of Social Media Research Methods. Eds. Luke Sloan and Anabel Quan-Haase. Los Angeles: SAGE, 2017. 573-92. Print.

Leist, Anja K. "Social Media Use of Older Adults: A Mini-Review." Gerontology 59.4 (2013): 378-84. Web. 10 Apr. 2018.

Lewis, Cynthia. "New Literacies." A New Literacies Sampler. Eds. Michele Knobel and Colin Lankshear. New York: Peter Lang, 2007. 229-37. Print.

Lillis, Theresa. Socolinguistics of Writing. Edinburgh: Edinburgh UP, 2013. Print.

Love, Meredith. "Composing Through the Performative Screen: Translating Performance Studies into Writing Pedagogy." Composition Studies 35.2 (2007): 11-30. Print.

Marsh-Dawson, Jeanie. @jeamada. Instagram. n.d. Web. 10 Apr. 2018.

---. “The Invisibility Myth Part 11: Coffin Dodgers Bus Tour." The Invisibility Myth. Blog. 31 July 2017. Web. 10 Apr. 2018.

Marsh-Dawson, Jeanie, et al. @goldiemagazineuk. Instagram. n.d. Web. 20 Apr. 2018.

Marwick, Alice. Status Update: Celebrity, Publicity, and Branding in the Social Media Age. New Haven: Yale UP, 2013. Print.

McKee, Heidi, and Kristine Blair. "Older Adults and Community-Based Technological Literacy Programs: Benefits \& Barriers to Learning." Community Literacy Journal 1.2 (2007): 13-39. Web. 10 Apr. 2018.

McKee, Heidi, and Dànielle Nicole DeVoss, eds. Digital Writing Research: Technologies, Methodologies, and Ethical Issues. Cresskill: Hampton P, 2007. Print.

McKee, Heidi, and James E. Porter. The Ethics of Internet Research: A Rhetorical, Case-Based Process. New York: Peter Lang, 2009. Print.

Meagher, Michelle. "Against the Invisibility of Old Age: Cindy Sherman, Suzy Lake, and Martha Wilson." Feminist Studies 40.1 (2014): 101-43. Web. 10 Apr. 2018.

Mediakix. "What Is a Lifestyle Blogger?" Mediakix. Santa Monica: Mediakix, 5 June 2015. Web. 10 Apr. 2018.

Moody, Harry. "Overview: What Is Critical Gerontology and Why Is It Important?” Voices and Visions of Aging: Toward a Critical Gerontology. Eds. Thomas R. Cole, W. Andrew Achenbaum, Patricia K. Jakobi, and Robert Kastenbaum. New York: Springer, 1993. xv-xli. Print.

Pecchioni, Loretta L., Hiroshi Ota, and Lisa Sparks. "Cultural Issues in Communication and Aging." Handbook of Communication and Aging Research. Eds. Jon F. Nussbaum and Justine Coupland. New York: Erlbaum, 2004. 167-98. Print.

Pew Research Center. “Social Media Fact Sheet." Pew Research Center: Internet \& Technology. Pew Research Center, 5 Feb. 2018. Web. 10 Apr. 2018.

Pigg, Stacey. "Researching Social Media Literacies as Emergent Practice: Changes in Twitter Use After Year Two of a Longitudinal Case Study." Literacy in Practice: Writing in Private, Public, and Working Lives. Eds. Patrick Thomas and Pamela Takayoshi. New York: Routledge, 2016. 17-31. Print.

Salmons, Janet. Doing Qualitative Research Online. Thousand Oaks: SAGE, 2016. Print.

Schmidt, Jan-Hinrik. "Practices of Networked Identity." A Companion to New Media Dynamics. Eds. John Hartley, Jean Burgess, and Axel Bruns. Chichester: Blackwell, 2013. 365-74. Print.

Schreurs, Kathleen, Anabel Quan-Haase, and Kim Martin. "Problematizing the Digital Literacy Paradox in the Context of Older Adults' ICT Use: Aging, Media Discourse, and SelfDetermination." Canadian Journal of Communication 42.2 (2017): 359-77. Print.

Selfe, Cynthia L., and Gail E. Hawisher. Literate Lives in the Information Age: Narratives of Literacy from the United States. Mahwah: Lawrence Erlbaum, 2004. Print. 
Shepherd, Ryan P. "FB in FYC: Facebook Use Among First-Year Composition Students." Computers and Composition 35 (2015): 86-107. Web. 10 Apr. 2018.

---. "Men, Women, and Web 2.0 Writing: Gender Difference in Facebook Composing." Computers and Composition 39 (2016): 14-26. Web.

Smith, Aaron, and Monica Anderson. Social Media Use in 2018. Pew Research Center: Internet and Technology. 1 Mar. 2018. Web. 10 Apr. 2018.

Stefonovic-Riley, Silvana. @embellish_or_perish. Instagram,n.d. Web. 10 Apr. 2018.

Stewart, Linda. "Come on in! Stepping into DMAC to Become a Digital Media Dweller." Computers and Composition. 36 (2015): 54-65. Web. 10 Apr. 2018.

Syverson, Margaret. “An Ecological View of Literacy Learning." Literacy 42.2 (2008): 109-17. Web. 4 Apr. 2018.

Tassie, Keisha Edwards, and Sonja M. Brown Givens, eds. Women of Color and Social Media Multitasking: Blogs, Timelines, Feeds, and Community. Lanham: Lexington, 2015. Print.

Tomlinson, Elizabeth. "First Encounters in Professional Cyberspace: Writers' Exploration of LinkedIn." Literacy in Practice: Writing in Private, Public, and Working Lives. Eds. Patrick Thomas and Pamela Takayoshi. New York: Routledge, 2016. 163-75. Print.

Townsend, Leanne, and Claire Wallace. Social Media Research: A Guide to Ethics. Aberdeen: Economic and Social Research Council/University of Aberdeen, 2016. Web. 10 Apr. 2018.

Twigg, Julia. Fashion and Age: Dress, the Body and Later Life. New York: Bloomsbury, 2013. Print.

Veum, Aslaug, and Linda Victoria Moland Undrum. “The Selfie as a Global Discourse." Discourse \& Society 29.1 (2018): 86-103. Web. 10 Apr. 2018.

Warner, Julie. “Adolescents' Dialogic Composing with Mobile Phones.” Journal of Literacy Research 48.2 (2016): 164-191. Web. 5 Apr. 2018.

We Are Social/Hootsuite. 2018 Q2 Global Digital Statshot. SlideShare, 17 Apr. 2018. Web. 5 May 2018.

Woodward, Kathleen. "Performing Age, Performing Gender.” NWSA Journal 18.1 (2006): 162-89. Web. 4 Apr. 2018. 